\title{
THE MAP PROPULSION SUBSYSTEM
}

\author{
Gary T. Davis* \\ NASA Goddard Space Flight Center / Code 574 \\ Greenbelt, MD 20771 USA
}

\section{Abstract}

This paper describes the requirements, design, integration, test, performance, and lessons learned of NASA's Microwave Anisotropy Probe (MAP) propulsion subsystem. MAP was launched on a DeltaII launch vehicle from NASA's Kennedy Space Center on June 30, 2001. Due to instrument thermal stability requirements, the Earth-Sun L2 Lagrange point was selected for the mission orbit. The L2 trajectory incorporated phasing loops and a lunar gravity assist. The propulsion subsystem's requirements are to manage momentum, perform maneuvers during the phasing loops to set up the lunar swingby, and perform stationkeeping at L2 for 2 years. MAP's propulsion subsystem uses 8 thrusters which are located and oriented to provide attitude control and momentum management about all axes, and delta- $\mathrm{V}$ in any direction without exposing the instrument to the sun. The propellant tank holds $72 \mathrm{~kg}$ of hydrazine, which is expelled by unregulated blowdown pressurization. Thermal management is complex because no heater cycling is allowed at L2. Several technical challenges presented themselves during $I \& T$, such as in-situ weld repairs and in-situ bending of thruster tubes to accommodate late changes in the observatory CG. Onorbit performance has been nominal, and all phasing loop, mid-course correction, and stationkeeping maneuvers have been successfully performed to date.

\section{MAP Mission Overview}

MAP is a MIDEX class mission with NASA's Goddard Space Flight Center and Princeton University as principal partners. MAP's single instrument measures the anisotropies in the cosmic microwave background (CMB). The mission objective is to produce a map of the $\mathrm{CMB}$ anisotropies with an angular resolution of 0.3 degrees. This map of the anisotropy distribution will help determine how structure formed in the early universe, determine the ionization history of the universe, and refine estimates of key cosmological parameters. An operational orbit about the Earth-Sun L2 Lagrange point was selected to give the instrument thermal stability. The science mission lifetime is two years of observations at $\mathrm{L} 2$.

\section{MAP Observatory Description}

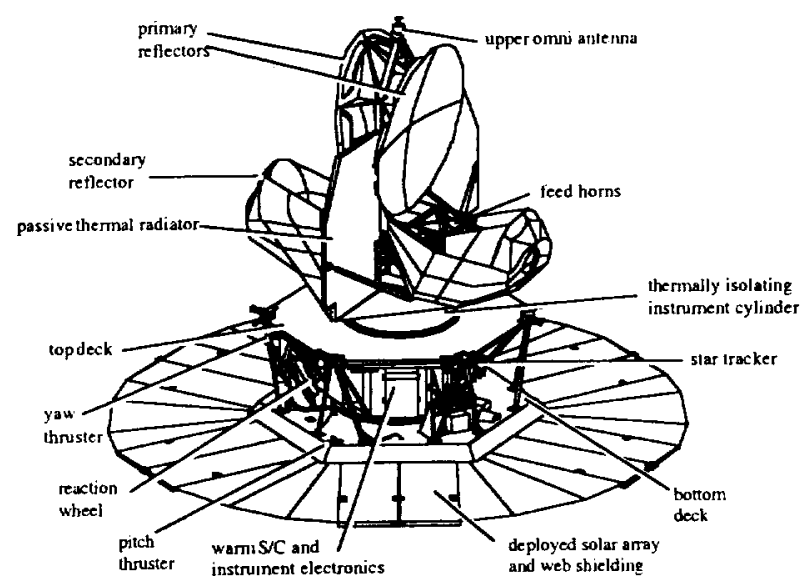

Figure 1: MAP Observatory Layout

\section{Mechanical Design}

The MAP observatory consists of a single science instrument and the spacecraft (Fig. 1). The instrument uses back-to-back composite primary and secondary reflectors that focus the signal into microwave feed horns. The signal is then amplified inside the instrument electronics box. The instrument is passively cooled via two aluminum surfaced honeycomb radiators. The spacecraft supports the instrument electronics and optics with a hexagonal composite hub and composite upper and lower decks. Major spacecraft components and electronics boxes are mounted to the outer sides of the hub and to the lower deck. Six solar panels with Multi-Layer Insulation (MLI) blankets between the panels are hinged at the lower deck. The solar panels provide power and shade the instrument from the sun. The propulsion subsystem is distributed throughout the spacecraft. The propellant tank and flow components are located inside the hex hub. Four thrusters and the fill and drain valves are mounted to the lower deck, and four thrusters are mounted under the upper deck.

\section{Electrical Design}

Primary propulsion commands are generated by the MIDEX ACS and C\&DH (MAC) box (Fig. 2). The Little MAC box (LMAC) provides redundant commands. Primary heater power is provided by the MAC box. The Power System Electronics (PSE) box powers the redundant heaters. Temperature telemetry is provided by the MAC box. The Voltage Regulation 
And In-Rush Limiter (VRAIL) box provides regulated power to selected propulsion heaters.

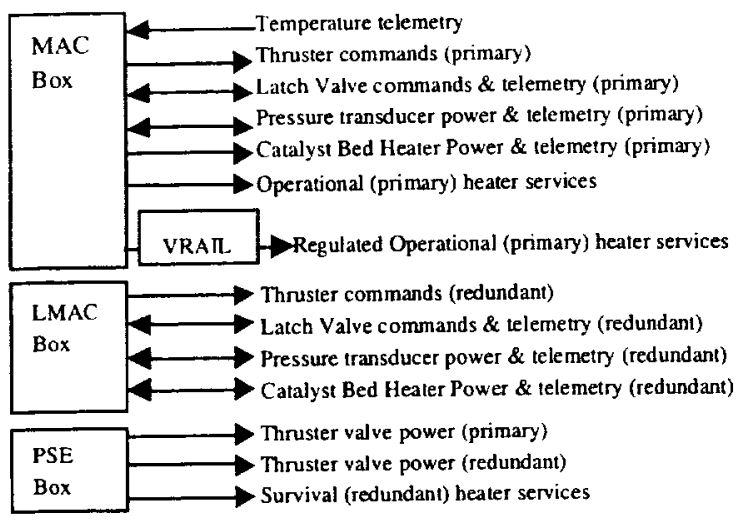

Figure 2: Propulsion Electrical Interfaces

\section{Trajectory Design}

A trajectory design using phasing loops was selected for the journey to L2 (Fig. 3). This trajectory begins with an elliptical orbit after separation from the Delta-II third stage. The "phasing loop" elliptical orbits are adjusted with maneuvers at apogee and perigee to set up the energy and timing for a lunar gravity assist.

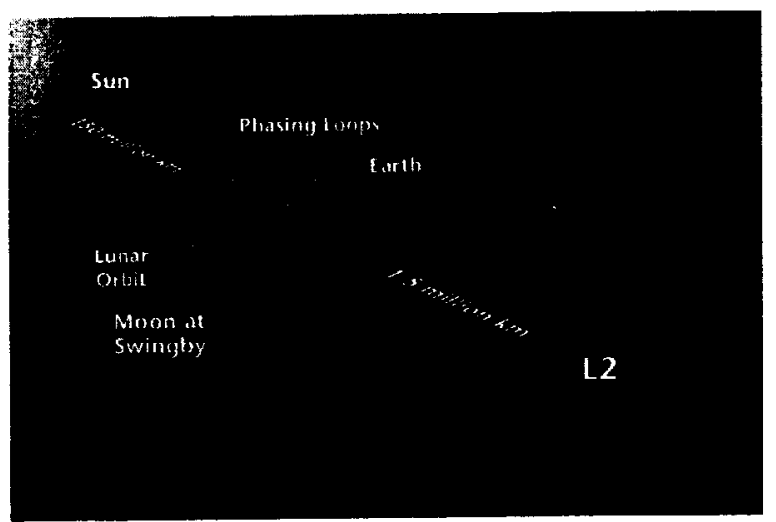

Figure 3: Phasing Loop Trajectory to L2

Three phasing loops were required for MAP's launch date. After the lunar swingby, mid-course corrections trim the trajectory during the 2 month cruise to L2. MAP then naturally falls into a 10.5 degree Lissajous orbit about L2. Small stationkeeping maneuvers (approximately 4 per year) maintain the Lissajous orbit at $\mathrm{L} 2$.

\section{Propulsion Subsystem Requirements}

\section{Functional Requirements}

The propulsion subsystem functional requirements include the following:

- Reduce tip-off rates after separation (contingency only)
- Perform maneuvers during the phasing loops to set up the swingby

- Perform mid-course corrections during the cruise to

L2

- Perform stationkeeping maneuvers at L2 for 2 years

- Perform shadow avoidance maneuvers at L2 for 2

years

- Perform attitude control during maneuvers and

momentum unloading for the life of the mission

\section{Attitude Constraints}

There are three factors that limit the allowable MAP attitude during thruster firing maneuvers:

1) The deployed solar array/sunshield must be within 53 degrees of the sun to be power-positive.

2) The ACS digital sun sensor needs to keep the sun within \pm 55 degrees in the $X Z$ plane and \pm 25 degrees in the $\mathrm{YZ}$ plane to maintain backup attitude determination. 3) After the lunar swingby, the $Z$ axis was limited to 19 \pm 5 degrees of the sun to preclude disturbing instrument thermal stability.

These attitude constraints, together with the orbit geometry, defined the spacecraft orientation for each maneuver. For example, perigee maneuvers uses the 4 $+\mathrm{X}$ thrusters; but the mid course corrections used either the $+Z$ or $-Z$ thrusters. The thruster firings maintained three-axis control and followed the velocity vector via an uploaded command quaternion table.

\section{Thermal Requirements}

All wetted propulsion components were designed to be kept between 10 and $40^{\circ} \mathrm{C}\left(10\right.$ to $55^{\circ} \mathrm{C}$ for propellant lines only) with primary "operational" and redundant "survival" heaters. The propulsion subsystem heaters were required to not cycle on/off at L2. The requirement that precluded heaters from cycling was a difficult challenge due to the widely varying thermal environment, unregulated bus voltage, limited power and telemetry resources, and expected MLI blanket property degradation.

\section{Propulsion Subsystem Design \& Analysis}

The initial MAP spacecraft design excluded functional redundancy for the subsystems. The initial propulsion subsystem design was a 6 thruster, blowdown pressurization monopropellant hydrazine subsystem. As the MAP observatory design matured, a comprehensive risk mitigation strategy was implemented to improve the overall system reliability. Two thrusters were added to the propulsion subsystem design to provide functional backup in case of any one thruster failure. The final propulsion subsystem design (Fig. 4) is a blowdown pressurization hydrazine subsystem with a single elastomeric diaphragm tank, 8 thrusters, a propellant filter, a pressure surge suppression orifice, and a latching isolation valve. A 
single pressure transducer provides pressure telemetry, and two service valves are used for propellant loading and pressurization.

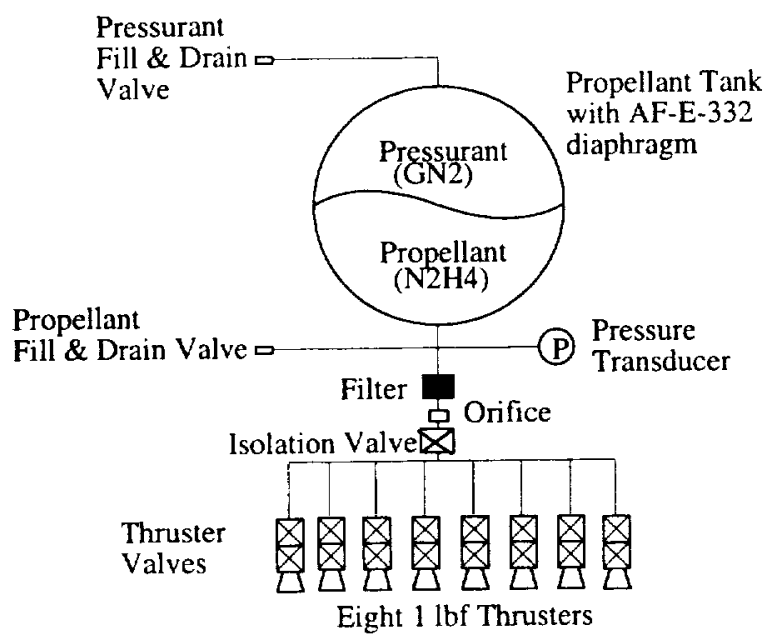

Figure 4: Propulsion Schematic

\section{Thruster Locations}

Thruster placement satisfies three requirements (Fig. 5 \& Table 2):

1) Delta- $V$ capability is provided in the $+X,+Z$, and $-Z$ directions while maintaining the orientation of the observatory with its solar panels towards the sun. 2) Torque capability is provided about all 3 spacecraft axes for momentum unloading during the mission and for attitude control during delta- $V$ maneuvers.

3) The failure of any one thruster can be tolerated by switching to a backup thruster mode (Table 1).
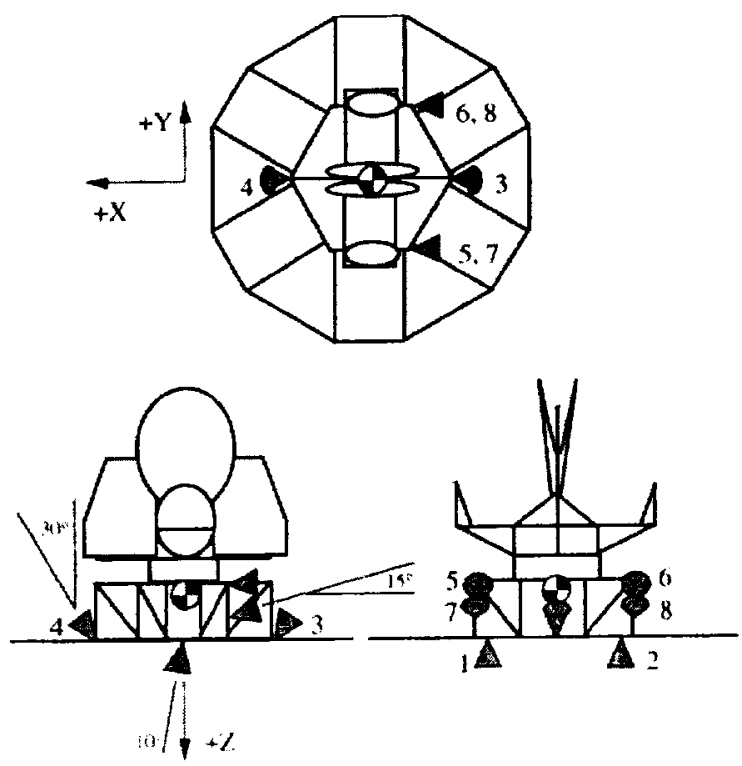

Figure 5: Thruster Locations

\begin{tabular}{|c|c|c|}
\hline Mode & $\begin{array}{l}\text { Primary } \\
\text { Thrusters }\end{array}$ & Backup Thrusters \\
\hline Delta V $+X$ & $5 \& 6 \& 7 \& 8$ & $\begin{array}{l}5 \& 6 \text { or } 7 \& 8 \text { or switch to } \\
\text { other delta-V direction }\end{array}$ \\
\hline Delta $V+Z$ & $3 \& 4$ & $\begin{array}{l}\text { switch to other delta- } V \\
\text { direction }\end{array}$ \\
\hline Delta V -Z & $1 \& 2$ & $\begin{array}{l}\text { switch to other delta-V } \\
\text { direction }\end{array}$ \\
\hline Torque $+\mathrm{X}(+$ roll $)$ & 1 & 8 \\
\hline Torque -X (- roll) & 2 & 7 \\
\hline Torque $+\mathrm{Y}(+$ pitch $)$ & 3 & $7 \& 8$ \\
\hline Torque -Y (- pitch) & 4 & $1 \& 2$ \\
\hline Torque $+Z$ (+ yaw) & 5 & 7 \\
\hline Torque $-Z$ (- yaw) & 6 & 8 \\
\hline
\end{tabular}

Table 1: Thruster Functions

\begin{tabular}{|c|c|c|c|c|c|c|}
\hline \multirow[b]{2}{*}{ THRUSTER } & \multicolumn{3}{|c|}{ Position from s/c origin } & \multicolumn{3}{|c|}{ Unit forse vector } \\
\hline & X POS. & Y POS. & $2 \mathrm{POS}$ & X FORCE & Y FORCE & Z FORCE \\
\hline & {$[\mathrm{m}]$} & {$[\mathrm{m}]$} & {$[\mathrm{m}\}$} & [unit vector] & \begin{tabular}{|l|} 
I unit vectorl \\
\end{tabular} & [unit vector] \\
\hline 1 & 0 & 0.912 & -0.007 & -0.1736 & 0 & -0.9848 \\
\hline 2 & 0 & 0.912 & 0.007 & .0 .1736 & 0 & -0.9848 \\
\hline 3 & -1.139 & 0 & -0.194 & 0.5 & 0 & 0.866 \\
\hline 4 & 1.139 & 0 & 0.194 & -0.5 & 0 & 0.866 \\
\hline 5 & -0.719 & -0.854 & -0.809 & 1 & 0 & 0 \\
\hline 6 & -0.719 & 0.854 & -0.809 & 1 & 0 & 0 \\
\hline 7 & -0.719 & -0.854 & -0.639 & 0.9659 & 0 & 0.2588 \\
\hline 8 & .0 .719 & 0.854 & -0.639 & 0.9659 & 0 & 0.2588 \\
\hline
\end{tabular}

Table 2: Thruster Positions \& Orientations

\section{Mechanical Description / Layout}

The propellant tank and HXCM (Hex Components Module) are located inside the hex hub (Fig. 6). The tank is located on the $\mathrm{Z} /$ spin axis and is attached to an aluminum support ring via 4 titanium fasteners with monoball supports. The monoball supports allow tank growth due to pressurization and thermal expansion. The HXCM consists of a bracket to which the propellant filter, isolation valve, pressure transducer, and orifice are mounted. 


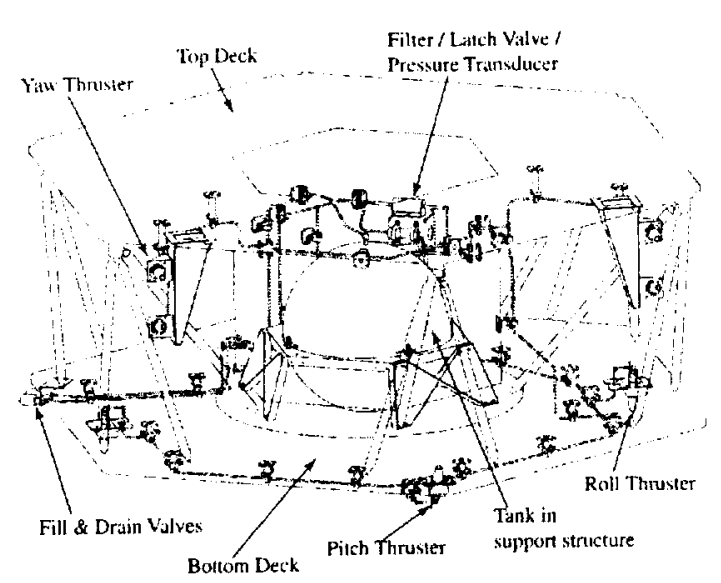

Figure 6: Propulsion Layout

The service valves are located on an aluminum bracket under the corner of the hexagonal lower deck. This location allows access to the valves with the solar array/sunshield in the stowed or deployed configuration. Access to the service valves is also possible through the Delta-II fairing door. The service valve location provides a low-point drain for contingency propellant offloading. Thrusters \#1-4 are mounted on aluminum brackets that are located inside holes in the lower deck. Thrusters \#5-8 are located on composite brackets that are attached to the underside of the upper deck.

\section{Thermal Design}

The temperature of wetted propulsion subsystem components are maintained within specified limits by primary and redundant heaters (Table 3 ). The primary "operational" heaters were designed to be "trimmed" (with variable resistors) during the observatory level thermal balance test to preclude heater cycling. The operational heaters are controlled by thermistor outputbased software. Three operational heater circuits also contain overtemperature thermostats. The redundant "survival" heaters are controlled by thermostats.

The wide range of thermal environment imposed on the propulsion subsystem presented difficult thermal design challenges. Pre-flight temperature predictions for the lower deck region were 70 to $75 \mathrm{C}$, while the inner hub was expected to be 20 to $30 \mathrm{C}$ and the upper deck was expected to be -50 to $-100 \mathrm{C}$. The operational heaters (primary) were not allowed to cycle after insertion into the mission orbit, and the thermostatically controlled survival heaters (redundant) were allowed to cycle only in the event of an operational heater failure. Since the spacecraft bus voltage was unregulated, several of the heater circuits were assigned to the regulated voltage bus from a VRAIL box to meet the thermal requirements.

\begin{tabular}{|c|c|c|}
\hline \multicolumn{2}{|c|}{$\begin{array}{l}\text { Operational Heater Services (Euch service powers entire circuit, } \\
\text { commanded via software: "*" denotes overtemperature thennostat } \\
\text { in circuit.) }\end{array}$} & $\begin{array}{l}\text { Power @ } 31.5 \\
\text { Volts }[W]\end{array}$ \\
\hline MAC C\&DH \#2 & Propellant Tank & 1.58 \\
\hline MAC C\&DH \#3 & $\begin{array}{l}\text { Intenal Propellant Lines } \\
\text { HXCM (Module inside hex hub) }\end{array}$ & 2.15 \\
\hline MAC C\&DH $\$ 5$ VRAIL 6 & 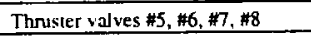 & 0.80 \\
\hline MAC C\&DH \#S VRAIL ] & Top Deck Thruster Brackets & 17.95 \\
\hline MAC C\&DH \#6 & Thiruster valves \#1 \& \#2 & 0.46 \\
\hline MAC C\&DH \#7 VRAIL 3 & - Top Deck Externa! lines & 1.32 \\
\hline MAC C\&DH \#8 VRALL 2 & Thruster values $\# 3 \& \& 4$ & 0.67 \\
\hline MAC C\&DH \#9 & - Vertical External Line & 0.12 \\
\hline MAC C\&DH $\$ 10$ & $\begin{array}{l}\text { Boltom Deck External Lines } \\
\text { Fill \& Drain Valve Lines }\end{array}$ & 2.92 \\
\hline \multicolumn{2}{|c|}{$\begin{array}{l}\text { Survival Heater Services (Each service is troken into several } \\
\text { circuits which are each indenendently controlled with thermostals.) }\end{array}$} & $\begin{array}{l}\text { Power @ } 29.5 \\
\text { Volts [W] } \\
\end{array}$ \\
\hline PSE Service 3 & $\begin{array}{l}\text { Propellant Tank } \\
\text { (8) Intemal Propellant Lines } \\
\text { HXCM (Module inside hex hub) }\end{array}$ & $\begin{array}{l}3.01 \\
0.39 * 8 \\
8.38\end{array}$ \\
\hline PSE Service 4 & $\begin{array}{l}\text { Upper Deck Thruster Bracket \#1 } \\
\text { (8) Thruster Valves \#1-\#8 }\end{array}$ & $\begin{array}{l}8.94 \\
1.47 * 8 \\
\end{array}$ \\
\hline PSE Service 5 & $\begin{array}{l}\text { Upper Deck Thruster Bracket \#2 } \\
\text { Fill \& Drain Valve } \\
\text { (7) Bottom Deck External Lines } \\
\text { (2) Fill \& Drain Valve Lines } \\
\text { Vertical Extemal Line } \\
\text { (4) Top Deck Extemal Lines }\end{array}$ & $\begin{array}{l}8.94 \\
2.60 \\
0.33 * 7 \\
0.33 \& 0.21 \\
0.79 \\
(0.97,0.52) * 2\end{array}$ \\
\hline \multicolumn{2}{|c|}{ Catbed Heater Services (Each service powers the entire circuit.) } & $\begin{array}{l}\text { Power } 28 \\
\text { Volts }[\mathrm{W}]\end{array}$ \\
\hline MAC ACE Service 3 & Thrusters 1 \& 2 primary & 10.82 \\
\hline MAC ACE Service 4 & Thusters 3 \& 4 primary & 10.82 \\
\hline MAC ACE Service 5 & Thussters $5 \& 6$ mimary & 10.82 \\
\hline MAC ACE Service 6 & Thrusters $7 \& 8$ primary & 10.82 \\
\hline LMAC ACE Service 3 & Thrusters 1 \& 2 redundant & 10.82 \\
\hline LMAC ACE Service 4 & Thrusters $3 \& 4$ redundant & 10.82 \\
\hline LMAC ACE Service 5 & Thrusters $5 \& 6$ redundant & 10.82 \\
\hline LMAC ACE Service 6 & Thrusters $7 \&$ \& redundint & 10.82 \\
\hline
\end{tabular}

Table 3: Heater Services

\begin{tabular}{|c|c|c|c|}
\hline Component & Qty. & Vendor & Note \\
\hline $\begin{array}{l}\text { Propellant } \\
\text { Tank }\end{array}$ & 1 & $\begin{array}{l}\text { PSI } \\
80362-1 \\
\end{array}$ & $\begin{array}{l}\text { TOMS-EP } \\
\text { protoflight }\end{array}$ \\
\hline $\begin{array}{l}\text { Isolation } \\
\text { Valve } \\
\end{array}$ & 1 & $\begin{array}{l}\text { Vacco } \\
\text { V1E10457-01 }\end{array}$ & TRMM spare \\
\hline $\begin{array}{l}\text { Pressure } \\
\text { Transducer }\end{array}$ & 1 & $\begin{array}{l}\text { Gulton Statham } \\
\text { PA 4089-400-24498 }\end{array}$ & TRMM spare \\
\hline Orifice & 1 & Creative Pathways & $\begin{array}{l}1.19 \mathrm{~mm}(0.0469 \\
\text { in) ID }\end{array}$ \\
\hline Filter & 1 & $\begin{array}{l}\text { Vacco } \\
\text { F0D10012.01 }\end{array}$ & COBE spare \\
\hline $\begin{array}{l}\text { Fill \& Drain } \\
\text { Valves }\end{array}$ & 2 & $\begin{array}{l}\text { Moog } \\
50-787 / 50-788 \\
\end{array}$ & $\begin{array}{l}3 \text { seals with } \\
\text { external cap }\end{array}$ \\
\hline Thrusters & 8 & $\begin{array}{l}\text { PRIMEX } \\
\text { MR-111C } \\
\end{array}$ & $\begin{array}{l}4.6 \mathrm{~N} @ 2.41 \mathrm{Mpa} \\
(350 \mathrm{psia})\end{array}$ \\
\hline Heaters & 112 & Minco, Tayco & Various sizes \\
\hline Thermistors & 25 & $\mathrm{YSI}$ & \\
\hline Thermostats & 73 & Elmwood & Various setpoints \\
\hline Tubing & N/A & $\begin{array}{l}\text { Tube Methods } \\
\text { MIL-T-8973, 304L }\end{array}$ & $\begin{array}{l}6.35 \mathrm{~mm}\left(0.25^{\prime \prime}\right) \\
\text { OD } 0.7 \mathrm{~mm} \\
\left(0.028^{\prime \prime}\right) \text { wall } \\
\end{array}$ \\
\hline Filtings & 25 & Creative Pathways & $304 \mathrm{~L}$ \\
\hline
\end{tabular}

Table 4: Component List 


\section{Flight Hardware / Components}

Several spare components from past flight projects were used in the design to reduce cost and increase schedule margin (Table 4). These include the TOMSEP protoflight propellant tank, COBE propellant filter, TRMM latch valve, and TRMM pressure transducer. The remaining components were procured as "off the shelf' designs.

\section{Propellant Budget}

The propellant budget included all required maneuvers for the trajectory to L2, momentum management, shadow avoidance, and stationkeeping at L2 for at least 2 years (Table 5). To account for thruster orientation angles, the delta- $\mathrm{V}$ modes were modeled with appropriate efficiencies. The propellant budget assumed the highest fuel usage thruster firing mode if the maneuver directions were not known.

\begin{tabular}{|l|l|l|}
\hline Category & Delta V [m/s] & Propellant [kg] \\
\hline Tip-off \& calibrations & 11 & 4.7 \\
\hline Phasing loop maneuvers & 110 & 40.1 \\
\hline Mid-course corrections & 10 & 5.0 \\
\hline Stationkeeping at L2 & 8 (for 2 years) & 4.0 \\
\hline Shadow Avoidance at L2 & 20 (for 2 years) & 10.0 \\
\hline Contingencies & 36 & 7.6 \\
\hline
\end{tabular}

Table 5: Propellant Budget

Because of the criticality of the phasing loop maneuvers, contingency propellant was included to make up for missed, aborted, or anomalous maneuvers. "Worst case" thruster performance, finite burn penalties, and ACS duty cycles were assumed.

The delta-V requirements for the phasing loop segment of the mission depended on launch date and launch vehicle dispersions. The 3-sigma velocity dispersion from the solid motor third stage of the launch vehicle was factored into the phasing loop delta$\mathrm{V}$ budget. A plot of various launch cases for 3 and 5 phasing loops during the Nov-Dec 00 window is shown in Fig. 7. The critical final perigee maneuver (Pfinal) was constrained to $30 \mathrm{~m} / \mathrm{s}$ because the delta- $\mathrm{V}$ required to correct for any errors after Pfinal would quickly become large. For example, a $5 \%$ error in executing a $30 \mathrm{~m} / \mathrm{s}$ Pfinal would grow into a $15 \mathrm{~m} / \mathrm{s}$ correction maneuver in 18 hours. The $15 \mathrm{~m} / \mathrm{s}$ Pfinal correction was included in all budgets.

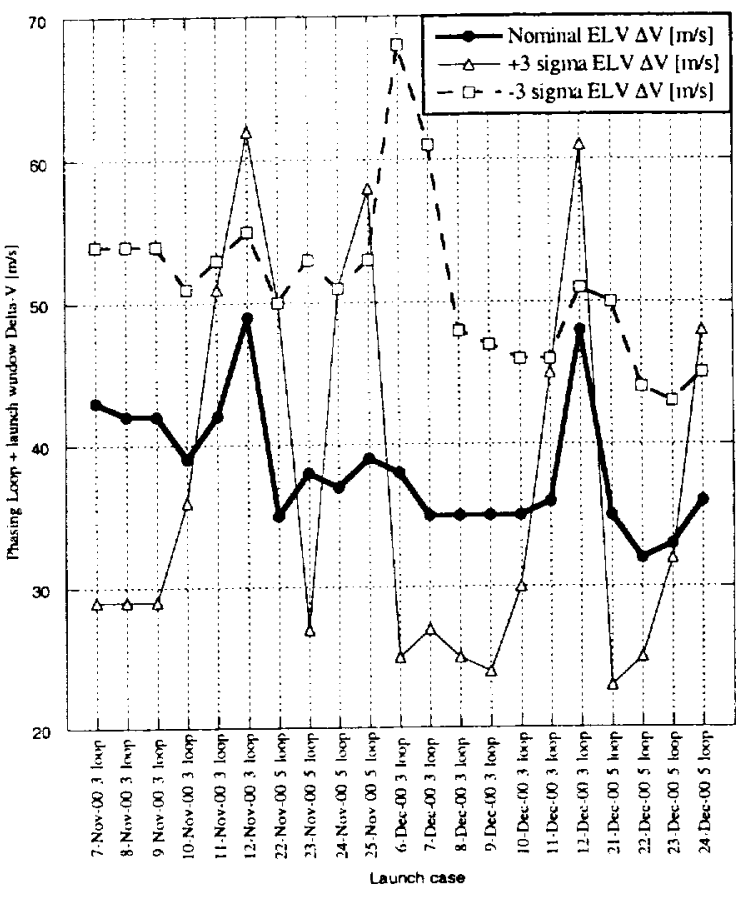

Figure 7: Phasing Loop Delta-V Launch Cases

\section{Pressure Drop \& Surge}

Analyses and tests were performed to predict potential surge pressures in case the latch valve needed to be opened with an evacuated thruster manifold. The propulsion subsystem was designed to be launched with the latch valve open with liquid propellant filling the entire manifold to the thruster valves. However, it was possible (e.g., ground operation error or leaking thruster valve prior to opening the latch valve) to establish conditions for high surge pressures. To reduce the magnitude of the pressure surge, an orifice was added upstream of the latch valve.

A full scale mockup of the thruster manifold was constructed. Surge tests were performed using water to simulate various surge conditions and to size the orifice. The chosen orifice inner diameter of $1.19 \mathrm{~mm}$ ( $0.0469 \mathrm{in})$ reduced the predicted peak surge pressure from 25.6 Mpa (3710 psia) to $7.74 \mathrm{MPa}$ (1123 psia).

\section{Plume Impingement}

Conservative plume analyses were performed to verify that heating rates on MAP observatory surfaces were acceptable, and to determine the plume forces/torques for each thruster. MLI blanket materials were changed to high temperature materials where required. The plume force/torque values were used by the ACS team to simulate the predicted duty cycles and attitude errors for all thruster modes. The observed onorbit plume force estimates are roughly one half the predicted analysis values. The pre-flight analytical predicts are shown in Table 6 . 


\begin{tabular}{|l|r|r|r|r|r|r|}
\hline Thruster & $\begin{array}{l}X \text { force } \\
{[\mathrm{N}]}\end{array}$ & $\begin{array}{l}\mathrm{Y} \text { force } \\
{[\mathrm{N}]}\end{array}$ & $\begin{array}{l}\mathrm{Z} \text { force } \\
{[\mathrm{N}]}\end{array}$ & $\begin{array}{l}\mathrm{X} \text { toryue } \\
{[\mathrm{Nm}]}\end{array}$ & $\begin{array}{l}\mathrm{Y} \text { torque } \\
{[\mathrm{Nm}]}\end{array}$ & $\begin{array}{l}\text { Z torque } \\
{[\mathrm{Nm}]}\end{array}$ \\
\hline 1 & 0 & 0 & 0 & 0 & 0 & 0 \\
\hline 2 & 0 & 0 & 0 & 0 & 0 & 0 \\
\hline 3 & -0.01 & 0 & -0.12 & 0 & -0.13 & 0 \\
\hline 4 & 0.01 & 0 & -0.12 & 0 & 0.13 & 0 \\
\hline 5 & 0 & 0 & 0.16 & -0.12 & 0.33 & 0 \\
\hline 6 & 0 & 0 & 0.16 & 0.12 & 0.33 & 0 \\
\hline 3 & 0 & 0 & 0.02 & -0.01 & 0.04 & 0 \\
\hline 8 & 0 & 0 & 0.02 & 0.01 & 0.04 & 0 \\
\hline
\end{tabular}

Table 6: Analytical Plume Forces \& Torques

\section{Propellant Slosh}

Analyses were performed to determine the nutation time constant of the spinning MAP/Delta-II $3^{\text {rd }}$ stage stack. The calculated time constant was $502 \mathrm{~s}$ at ignition and $253 \mathrm{~s}$ at burnout, well above Delta's ignition/burnout requirements of $150 \mathrm{~s} / 50 \mathrm{~s}$, respectively. On-orbit data confirms the results of the slosh analyses performed by the MAP ACS group, which indicated that the propellant slosh would be negligible and would not present any control problems.

\section{Propulsion Subsystem Integration \& Test}

Integration of the propulsion subsystem took place in Class 10000 cleanrooms at the GSFC. All parts and components were cleaned and verified per MIL-STD1246C Level 100, except no metal particles above 25 microns were allowed. All test fluids were filtered to 0.5 microns.

A limitation on the number of thruster valve dry cycles was imposed on all tests throughout the I\&T phase of the program. The maximum number of dry cycles was thruster \#8 with 62 dry cycles.

\section{Integration \& Test Flow}

The major propulsion subsystem related I\&T activity flow is shown in Fig. 8.

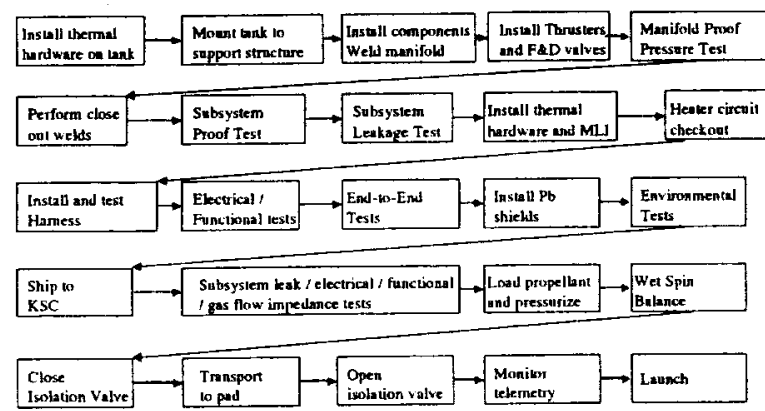

Figure 8: Propulsion I\&T Flow

\section{Welding Blowout Problems \& Repair}

Two thruster closeout welds blew out during propulsion I\&T (Fig. 9). In each case the blowouts occurred due to excessive purge gas pressure which built up as the weld was being performed.
Each blown-out weld was successfully repaired using a modified procedure from the TRMM program. The repair involved manually filling the "blow hole" with filler material (Fig. 10), then performing a machine orbital weld pass over the repair (Fig 11). Qualification welds that simulated the blowout holes and repair procedure were tested to validate each repair.

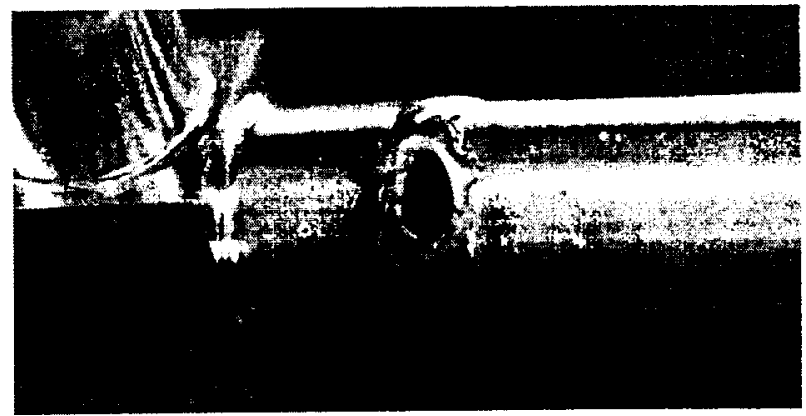

Figure 9: Weld Blowout

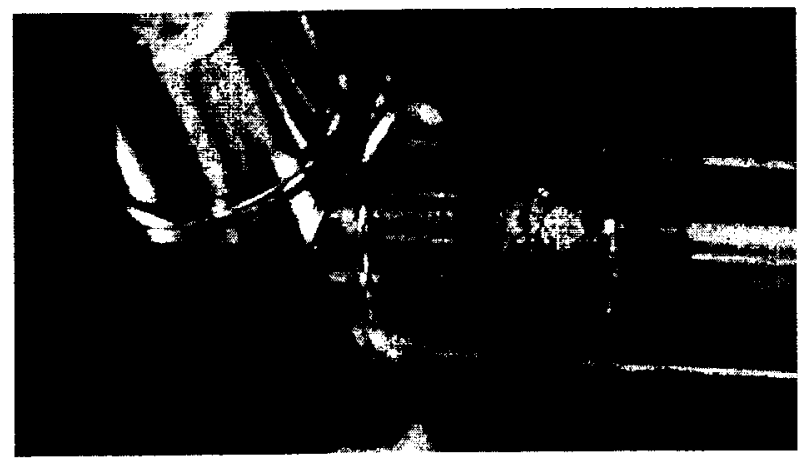

Figure 10: Weld Hand Repair (Step 1)

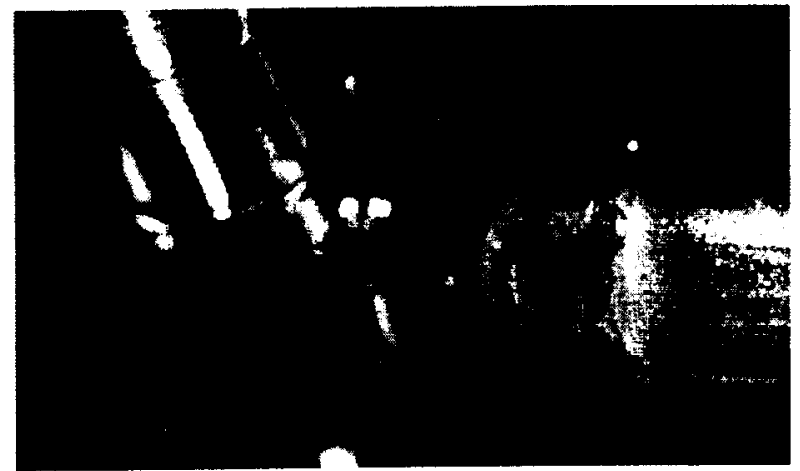

Figure 11: Weld Orbital Repair (Step 2)

\section{Thermal Hardware Installation}

Installation of thermal hardware required the application of thousands of pieces of aluminum tape and more than 100 heaters. After the spacecraft was assembled, analysis regarding deep dielectric discharge concluded that all of the spacecraft harness needed to be shielded with lead and that all floating conductors needed to be grounded. Fig. 12 shows the buildup of 
aluminum tape, heaters, aluminum tape, wires, lead shield tape, and thermal MLI blankets.

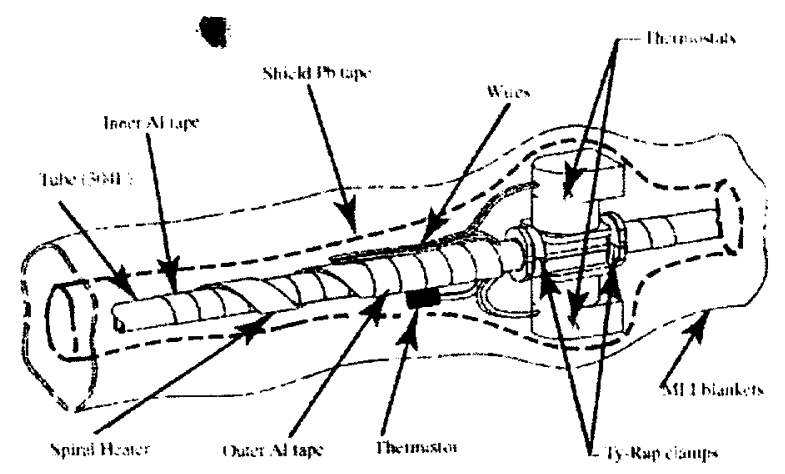

Figure 12: Tubing Thermal Hardware Layout

\section{Center-Of-Mass Issue \& Remedy}

After the spacecraft was constructed and the propulsion subsystem was completely integrated and tested, it was discovered that the overall MAP observatory center of mass had migrated in the $-Z$ direction. This migration caused one of the thruster backup modes to be ineffective due to the loss of negative pitch torque from thrusters \#5 \& \#6. In order to restore the lost backup mode, the propellant lines to roll thrusters \#1 \& \#2 needed to be bent 10 degrees to provide negative pitch torque.

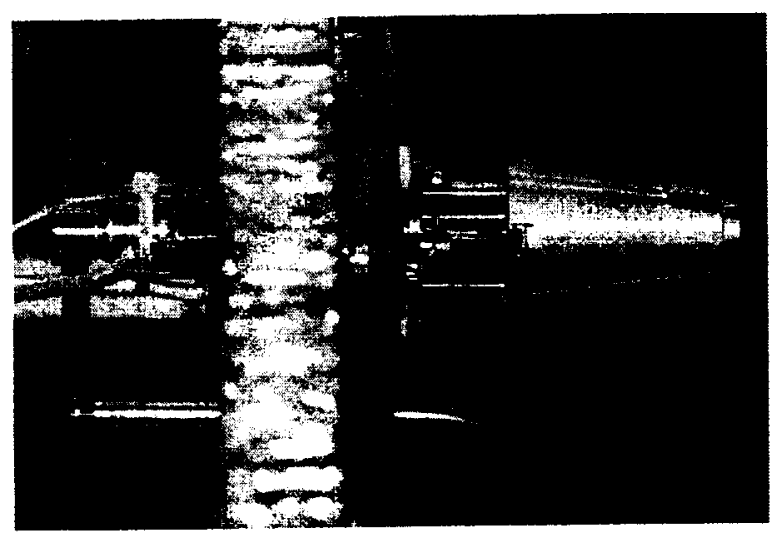

Figure 13: Roll Thruster Before Bending

To avoid having to cut the thruster propellant line, a custom tool was designed for the limited work space and used to bend each thruster line in-situ (Fig. 13 \& 14). On-orbit data confirms the accuracy to which these difficult thruster re-alignments were performed. Ref. 1 provides more detail on the thruster bending.

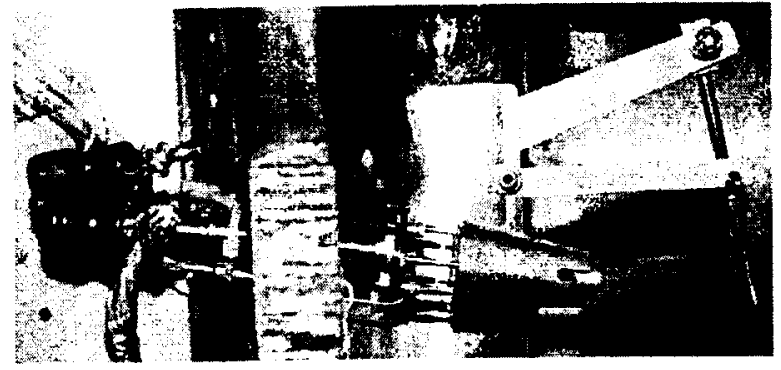

Figure 14: Roll Thruster \& Bend Tool After Bending

\section{Propulsion Subsystem Testing}

Most tests were repeated at the component, subsystem, spacecraft, and observatory levels of assembly to verify performance and establish trending data. The major tests are described below.

\section{Proof Pressure Tests}

Before the propellant tank closeout weld was performed, the manifold downstream of the tank was proof tested to $5.52 \mathrm{MPa}(800 \mathrm{psia})$. This proof pressure test took the worst case latch valve backpressure relief into account. After the tank closeout weld was completed, a proof pressure test of the entire subsystem was performed using pressurized helium at $3.66 \mathrm{MPa}$ (531 psig).

\section{Leakage Tests}

All welds and the Fill and Drain Valve primary seats were leak tested at MEOP ( $2.41 \mathrm{MPa} / 350 \mathrm{psig})$ with a helium mass spectrometer. The tank diaphragm, thruster valves (both upstream and downstream seats), and the isolation valve were leak tested using a liquid displacement meter. The tank diaphragm was tested at $35 \mathrm{kPa}$ (5 psid). Thrusters were leak tested at MEOP, $690 \mathrm{kPa}$ (100 psig), and $345 \mathrm{kPa}$ (50 psig). The isolation valve was tested at MEOP, $690 \mathrm{kPa}(100$ psig), and $172 \mathrm{kPa}$ (25 psig).

\section{Electrical / Functional Tests}

The electrical / functional tests consisted of the following tests:

- Pressure transducer verification

- Isolation valve actuation, response time, and position indication

- Thruster valve response time

- Thruster gas flow impedance at $103 \mathrm{kPa}$ (15 psig)

\section{Thermal Hardware Tests}

Integrity of thermal hardware was verified by measuring the resistance of the circuits, checking the resistance of the temperature sensors, and actuating all thermostats with cold spray or heat gun.

\section{End-To-End Tests}

The purpose of the end-to-end tests was to verify that commands issued to the ACS electronic boxes 
actuated the correct thrusters. Both MAC and LMAC thruster and isolation valve commands were verified. Catalyst bed heater tests and pressure transducer verification were also performed.

\section{Aliveness / Functional / CPT Tests}

After the instrument was integrated to the MAP spacecraft, three types of Observatory-level tests were performed, aliveness tests, functional tests, and Comprehensive Performance Tests (CPTs). Typical propulsion functions that were tested are as follows:

- Cycle all heater services ( $<2$ minutes of on-time)

- Cycle valve driver power

- Verify all temperature sensor readings

- Pressure transducer verification

- Cycle catalyst bed heaters (<30 seconds on-time)

- Simulated thruster commands (to GSE only, not real valves)

- Simulated latch valve commands (to GSE only, not real valve)

Safeguards were in place to avoid overheating the catalyst beds and to avoid inadvertent cycling of the thruster and latch valves. Power to thermal heaters were limited to 2 minutes duration (catalyst beds less than 30 seconds). Thruster and latch valve electrical "enable" plugs were not installed during these tests, so valve dry cycling was precluded. All thruster valve commands were monitored by valve simulators.

\section{Acoustic / Vibration / Shock Tests}

During the spacecraft structure acoustic test, the response of the upper deck (dummy mass) thrusters exceeded the qualification level of the thrusters. The observed response was 45 overall Grms with a peak of $117 \mathrm{G}^{\wedge} 2 / \mathrm{Hz}$ at $144 \mathrm{~Hz}$. The high loads were caused by interaction of the lightweight composite upper deck and thruster brackets. Detailed analyses were performed to determine the natural frequencies and determine the efficacy of damping approaches.

Offline tests at GSFC characterized promising damping methods. Viscoelastic material (VEM) was added to two bays of the upper deck on both top and bottom surfaces. The outer edge of the upper deck was also stiffened with damping material on two bays. Selected thruster bracket surfaces were stiffened and covered with VEM. Silicone rubber was placed at the interfaces between each individual thruster bracket to the large bracket, and at the interface between the large bracket and the upper deck. The total damping materials' mass was $2.3 \mathrm{~kg}$.

The observatory level acoustic test verified that the damping was very effective. The maximum upper deck thruster loads were 2.83 overall Grms with a peak of $0.13 \mathrm{G}^{\wedge} 2 / \mathrm{Hz}$ at $70 \mathrm{~Hz}$. Subsequent observatory level random vibration and shock tests were conducted without incident. The thruster vendor visually inspected the thrusters for damage at the GSFC.

\section{Thermal Vacuum \& Thermal Balance Tests}

The thermal vacuum and thermal balance tests were critical in trimming the primary propulsion heaters and characterizing the overall thermal performance of the observatory. The test was planned in three parts: a thermal vacuum test to characterize the system, a chamber break to perform modifications, and a thermal balance test to verify thermal performance.

During the planned chamber break between tests, several thermal hardware components were replaced and the flight trim resistors were installed. All thermal hardware changes and trim resistors were verified during the thermal balance test. Thruster valve leakage and actuation were verified during the thermal balance test by using Xenon tracer gas.

\section{Trim Resistors}

During the thermal vacuum test, the propulsion primary (operational) heaters were sized with trim resistors to vary the amount of heater power in each circuit. The 33 trim resistor circuits were wired outside the chamber and resistance values were individually adjusted until the desired temperature characteristics were met. All operational circuits and the propellant tank survival circuits were trimmed.

\section{Chamber Break}

The following work was performed during the chamber break:

- Installed flight trim resistors

- Relocated valve thermostats for thrusters \#1-\#4

- Installed higher power heater and an additional blanket for the propellant fill and drain valve - Installed more heaters, changed thermostat setpoints, and added copper tape to the upper deck thruster brackets to keep thrusters \#5-\#8 temperatures within safe limits

\section{Launch Site Activities}

Pre-fueling tests at the launch site included complete functional tests, leakage tests, and an end-to-end thruster mode test that simulated all the delta- $V$ modes of the spacecraft. As a launch site service, KSC provided the propellant loading and pressurization logistics support, GSE, and personnel. KSC and GSFC technicians and engineers trained together and worked side-by-side in Self-Contained Atmospheric Personnel Ensemble (SCAPE) suits during the loading operations. After pressurization, the latching isolation valve was closed to maximize personnel safety. The latch valve was opened after the Delta-II fairing was installed. 


\section{On-Orbit Performance}

On June 30, 2001, MAP was launched on a Delta-II 7425-10. The launch events were nominal. Once the solar array/sunshield deployment was completed and the ACS and other subsystems were checked, the propulsion subsystem was incrementally tested and then used for a series of maneuvers to enable the lunar swingby en route to $\mathrm{L} 2$.

\section{Thruster "One-Shot" Pulses And $\Delta \mathrm{H}$}

One-shot pulses of $400 \mathrm{~ms}$ duration were sent to each thruster to verify thruster functionality and polarity. These tests were performed twice on the MAC box to verify that no bubbles were in the thruster lines. Once the polarity and function of the thrusters were verified, a $\Delta H$ maneuver was performed to reduce the onboard momentum. One-shots were then performed with the LMAC box to verify those command paths, since the LMAC would be used for all subsequent maneuvers. The torques imparted to the spacecraft by the one-shot and $\Delta \mathrm{H}$ firings were approximately $73-82 \%$ of the calculated steady-state value due to the short pulse length and resultant low thruster temperatures.

\section{Calibration Maneuvers}

During the phasing loops, each primary thruster mode $(+X,+Z$, and $-Z)$ was tested with short calibration burns (Table 7 ). The three calibration maneuvers, $\mathrm{A} 1, \mathrm{~A} 2$, and $\mathrm{A} 3$, were performed during non-critical parts of the trajectory (at apogee 1,2 , and 3 ). The first calibration, $A 1$, tested the $+X$ mode since that mode would be needed for a maneuver at P1. Duty cycles for all three thruster modes were better than expected, most likely due to conservative plume torque analyses. Thrust scale factors (TSF) were determined from the calibrations to plan the firing duration for subsequent maneuvers, where TSF $=$ actual $\Delta V$ from tracking data / expected $\Delta \mathrm{V}$ from analysis model. As shown in Fig. 15, each thruster mode has a slightly different TSF range.

The propulsion and trajectory design teams independently calculated TSF values (TSFP for propulsion). Excellent agreement is shown for both performance models, especially considering the short duration of some of the maneuvers, where tracking and orbit determination inaccuracies could contribute substantially to the error.

\begin{tabular}{|l|l|l|r|r|r|}
\hline Maneuver & $\begin{array}{l}\text { Date } \\
{[\text { GMT] }}\end{array}$ & Mode & $\begin{array}{l}\text { Duration } \\
\text { [sec] }\end{array}$ & $\begin{array}{l}\text { Propeilant } \\
\text { Used [kg] }\end{array}$ & $\begin{array}{l}\text { Delta-V } \\
\text { [n/s] }\end{array}$ \\
\hline $\begin{array}{l}\text { Thnister } \\
\text { One-shots }\end{array}$ & $\begin{array}{l}01-1821 \\
01-183\end{array}$ & N/A & $\begin{array}{l}400 \mathrm{~ms} \\
\text { each }\end{array}$ & $\begin{array}{l}0.025 \mathrm{~kg} \\
\text { total }\end{array}$ & N/A \\
\hline A1 cal & $01-185$ & $+\mathrm{X}$ & 105.8 & 0.841 & 1.922 \\
\hline $\mathrm{P} 1$ & $01-189$ & $+\mathrm{X}$ & 1275.4 & 8.806 & 20.194 \\
\hline $\mathrm{A} 2 \mathrm{cal}$ & $01-193$ & $+\mathrm{Z}$ & 40.0 & 0.118 & 0.254 \\
\hline $\mathrm{P} 2$ & $01-198$ & $+\mathrm{X}$ & 176.1 & 1.098 & 2.514 \\
\hline $\mathrm{A} 3 \mathrm{cal}$ & $01-202$ & $-\mathrm{Z}$ & 43.4 & 0.137 & 0.296 \\
\hline $\mathrm{P3}$ & $01-207$ & $+\mathrm{X}$ & 542.9 & 3.229 & 7.410 \\
\hline $\mathrm{P3C}$ & $01-208$ & $+\mathrm{X}$ & 23.8 & 0.137 & 0.308 \\
\hline $\mathrm{MCCl}$ & $01-218$ & $+\mathrm{Z}$ & 17.8 & 0.048 & 0.103 \\
\hline $\mathrm{MCC}$ & $01-257$ & $-\mathrm{Z}$ & 6.6 & 0.020 & 0.042 \\
\hline SK1 & $02-014$ & $+\mathrm{Z}$ & 72.0 & 0.197 & 0.435 \\
\hline
\end{tabular}

Table 7: Flight Maneuver Summary

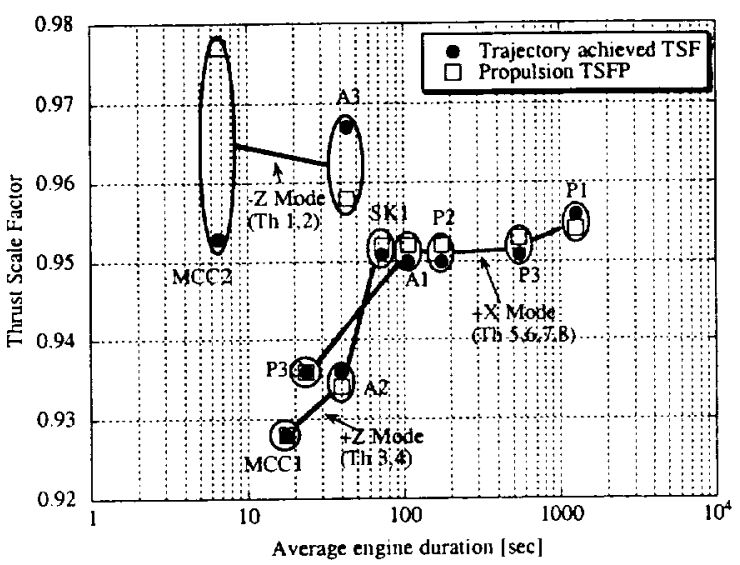

Figure 15: Maneuver Thrust Scale Factor (TSF)

\section{Phasing Loop Maneuvers}

The critical phasing loop maneuvers were executed at $\mathrm{P} 1, \mathrm{P} 2$, and $\mathrm{P} 3$ using the four thruster $+\mathrm{X}$ thruster mode (Table 7). P1 was the largest maneuver at 20.2 $\mathrm{m} / \mathrm{s}$ and $1275 \mathrm{~s}$ duration. The final perigee, $\mathrm{P} 3$, was the most critical since it set up the lunar swingby. Errors in the $\mathrm{P} 3$ firing would propagate quickly and require increasingly large delta-V to correct. The P3 correction, P3C, was executed as planned 18 hours after P3. The swingby was performed without incident.

\section{Mid-Course Corrections}

After the lunar swingby, two small mid-course corrections, MCC1 \& MCC2, were performed to trim the trajectory to L2 (Table 7). After the lunar swingby, the thermal constraint was imposed to keep the instrument cool and stable, so the $+Z$ and $-Z$ thruster modes were used.

\section{Stationkeeping at L2}

To date, one stationkeeping maneuver has been performed (Table 7). SK1 was a very short maneuver that was sufficient to maintain the L2 orbit for at least 6 months. Stationkeeping maneuvers will be performed at 4 month intervals with SK2 is scheduled for 8 May 02 . No shadow avoidance maneuvers are expected for the life of the mission. 
No backup thruster modes have been used thus far; all maneuvers have been performed within requirements with very little post-calibration error.

\section{Thermal Performance}

All heater circuits have performed as designed, keeping all components within acceptable temperatures with no heater cycling.

\section{Bottom Deck Heating}

The temperature on the sun-side of the spacecraft warmed at $1.5 \mathrm{C}$ per month as MAP's trajectory took it closer to the sun. MLI blanket degradation augmented the higher than predicted temperature increase. The maximum wetted component temperature observed was $55.5{ }^{\circ} \mathrm{C}$ on thruster valve \#1. Spacecraft temperatures have stabilized now that the trajectory is moving away from the sun and MLI property degradation has slowed. Current on orbit temperatures are shown in Table 8.

\begin{tabular}{|l|c|}
\hline Component / Location & Temperature on 4 Apr 02 [C] \\
\hline Propellant Tank (10p, bottom) & $34,0,33.9$ \\
\hline HXCM in bex hub & 27.0 \\
\hline Inner hex line & 28.4 \\
\hline Top deck lines & $22.1,23.8$ \\
\hline Vertical line & 20.5 \\
\hline Bottom deck lines & $43.5,38.5,38.5,43.6$ \\
\hline Fill \& Drain lines & $33.4,39.4$ \\
\hline Fill \& Drain Valve & 41.3 \\
\hline Upper Deck Thuster Brackets & $34.7,32.2$ \\
\hline Thruster Valves $(1,2,3,4,5,6,7,8)$ & $53.2,48.1,31.5,33.9,21.7,20.3,23.9 .22 .3$ \\
\hline Catalyst Beds (1, 2,3,4,5,6.7,8) & $110.9,116.3,104,13.8,-4.3,-4,3,-2.3,-2.3$ \\
\hline
\end{tabular}

Table 8: Propulsion Flight Temperatures

\section{Lessons Learned}

There were relatively few problems with the MAP propulsion subsystem from the design phase through launch. The definition, flowdown, and traceability of mission and system-level requirements early in the design process were critical factors in controlling the number of problems. The adherence to the guidelines for the requirements validation of the components and subsystem - "Test how you plan to fly; fly how you have tested." - was another key factor in reducing the number of problems.

There were two significant problems to resolve that resulted in an increase in cost and schedule. These problems were attributed to errors in defining systemlevel requirements during the design phase.

1: Problem: The spacecraft center of mass migrated outside of the critical volume for maintaining adequate thruster control torque authority for some backup modes. The problem was discovered after the spacecraft had been assembled.

Cause: Failure to implement a process to track spacecraft center-of-mass migration during the design/build phase of the project.
Resolution: Tools were developed to perform in-situ bending of thruster manifold to re-align two thrusters.

2: Problem: Radiation exposure analysis concluded that the spacecraft harness needed to be shielded to prevent charge buildup on the spacecraft. The problem was discovered after the spacecraft had been assembled.

Cause: Failure to adequately define the radiation belt environment during the phasing loops and analyze the resultant spacecraft charge buildup during the design phase of the project.

Resolution: The spacecraft harness was wrapped with lead shielding and all floating conductors were identified and grounded.

\section{Summary}

The MAP propulsion subsystem was designed, built, tested, and operated by the GSFC Propulsion Branch. A nominal Delta-II launch and nominal MAP propulsion subsystem performance resulted in the use of only $14.6 \mathrm{~kg}$ of propellant for phasing loop maneuvers, lunar gravity assist, and mid-course correction maneuvers to safely reach L2. All propulsion subsystem on-orbit requirements have been met and there is sufficient propellant remaining for an extended MAP science mission.

\section{Acknowledgements}

The success of the MAP propulsion subsystem is due to the dedication and skill of the technicians and engineers who designed, built, and tested the propulsion subsystem and supported its launch site and mission operations.

\section{Acronym List}

$\begin{array}{ll}\Delta H & \text { Change in momentum } \\ \Delta V & \text { Change in velocity } \\ \text { ACS } & \text { Attitude Control Subsystem } \\ \text { An } & \text { Apogee n } \\ \text { C\&DH } & \text { Command \& Data Handling } \\ \text { CG } & \text { Center of Gravity } \\ \text { CMB } & \text { Cosmic Microwave Background } \\ \text { COBE } & \text { Cosmic Background Explorer } \\ \text { CPT } & \text { Comprehensive Performance Test } \\ \text { GN2 } & \text { Gaseous nitrogen } \\ \text { GSE } & \text { Ground Support Equipment } \\ \text { GSFC } & \text { Goddard Space Flight Center } \\ \text { HXCM } & \text { HeX Components Module } \\ \text { I\&T } & \text { Integration and Test } \\ \text { KSC } & \text { Kennedy Space Center } \\ \text { L2 } & \text { Second Earth-Sun Lagrange point } \\ \text { LMAC } & \text { Little Midex ACS \& D\&DH } \\ \text { MAC } & \text { Midex ACS \& C\&DH } \\ \text { MAP } & \text { Microwave Anisotropy Probe } \\ \text { MCCn } & \text { Mid Course Correction n } \\ \text { MEOP } & \text { Maximum Expected Operating Pressure } \\ \text { MIDEX } & \text { Medium Explorer class } \\ \text { MLI } & \text { Multi-Layer Insulation (thermal blankets) } \\ \text { N2H4 } & \text { Hydrazine } \\ \text { NASA } & \text { National Aeronautics and Space Administration }\end{array}$

